\title{
Canine malignant hemangiosarcoma as a model of primitive angiogenic endothelium
}

\author{
Susan P Fosmire ${ }^{1}$, Erin B Dickerson ${ }^{2}$, Allyson M Scott ${ }^{3}$, Stacie R Bianco ${ }^{1}$, Marilyn J \\ Pettengill $^{3}$, Heather Meylemans ${ }^{1}$, Marcia Padilla ${ }^{2}$, Ashley A Frazer-Abel ${ }^{1}$, Nasim Akhtar ${ }^{2}$, \\ David M Getzy ${ }^{4}$, John Wojcieszyn ${ }^{5}$, Matthew Breen ${ }^{3}$, Stuart C Helfand ${ }^{2,6}$ and Jaime F \\ Modiano ${ }^{1,7}$
}

\begin{abstract}
${ }^{1} A M C$ Cancer Research Center and Integrated Department of Immunology, University of Colorado Health Sciences Center, Denver, CO, USA; ${ }^{2}$ Department of Medical Sciences, School of Veterinary Medicine, University of Wisconsin, Madison, WI, USA; ${ }^{3}$ Department of Molecular Biomedical Sciences, College of Veterinary Medicine, North Carolina State University, Raleigh, NC, USA; ${ }^{4}$ Idexx Veterinary Services, Broomfield, CO, USA; ${ }^{5}$ IHC Services, Smithville, TX, USA; ${ }^{6}$ University of Wisconsin Comprehensive Cancer Center, Madison, WI, USA and ${ }^{7}$ University of Colorado Cancer Center, Denver, CO, USA
\end{abstract}

\begin{abstract}
Hemangiosarcoma (HSA) is a common untreatable cancer of dogs that resembles human angiosarcoma. Detailed studies of these diseases have been historically hindered by the paucity of suitable reagents. Here, we show that expression of CD117 (c-Kit) can distinguish primitive (malignant) from mature (benign) proliferative endothelial lesions, and we describe eight independent cell lines derived from canine HSA explants. Endothelial origin was confirmed by sustained expression of surface CD105 (endoglin), CD146 (MUC18), and CD51/CD61 $\left(\alpha_{v} \beta_{3}\right.$ integrin). The cell lines showed anchorage-independent growth and were motile and invasive when cultured on a basement membrane matrix. They required endothelial growth factors for growth and survival, and they could be induced to form tubular structures resembling blood vessels when cultured under low calcium conditions. The formation of vessel-like structures was blocked by nicotine, and restored by FK506, suggesting that 'nuclear factor of activated T cells' activity prevents differentiation of these cells. In summary, these cell lines represent a unique and novel resource to improve our understanding of endothelial cell biology in general and canine HSA in particular.
\end{abstract}

Laboratory Investigation (2004) 84, 562-572, advance online publication, 5 April 2004; doi:10.1038/labinvest.3700080

Keywords: canine; endothelial cells; angiosarcoma; angiogenesis; CD117; NFAT; nicotine

Canine hemangiosarcoma (HSA) arises from transformed vascular endothelial cells, most commonly in the spleen, right atrium, or subcutis. The ontogeny of HSA cells can be confirmed by the expression of selected endothelial markers such as CD31 and Factor VIII-related antigen (vWF) ${ }^{1,2}$ Local infiltration and systemic metastases are the common growth patterns and metastatic sites are widespread, with lung and liver being the most frequently affected organs. $^{3,4}$ Morbidity and mortality is often due to acute internal hemorrhage secondary to tumor rupture. Despite surgery and intensive chemotherapy, the median survival time for dogs diagnosed with HSA is little more than 6

Correspondence: JF Modiano, AMC Cancer Research Center, 1600 Pierce Street, Denver, CO 80214, USA.

E-mail: modianoj@amc.org

Conflict of interest: The authors report no conflict of interest. Received 21 November 2003; revised 21 January 2004; accepted 21 January 2004; published online 5 April 2004 months. ${ }^{5-8}$ This naturally occurring disease of dogs resembles human angiosarcoma. Angiosarcomas are uncommon soft tissue sarcomas that can arise in a variety of locations, including liver, spleen, skin, breast, and endocrine organs. $^{9-11}$ Among these tumors, specific subtypes are associated with a variety of risk factors, such as occupational exposure to vinyl chloride for hepatic angiosarcoma, ${ }^{12,13}$ radiation therapy for mammary angiosarcoma, ${ }^{14-19}$ HIV-1 infection in the case of Kaposi sarcoma, ${ }^{20}$ and heritable defects in the VHL tumor suppressor gene in human infantile angiosarcomas and hemangiomas. ${ }^{21}$ Exposure to ionizing radiation seems to be a shared risk factor for development of HSA in dogs. ${ }^{22}$ As is true for canine HSA, treatment of human angiosarcomas can be challenging and is frequently unrewarding. ${ }^{9,11,23}$

In part, the paucity of effective treatments for endothelial cancers is due to the lack of appropriate reagents to study these diseases. ${ }^{24-29}$ Thus, our objective was to establish and characterize a cohort 
of canine HSA cell lines that could be used to explore the molecular and cellular features of this disease and that could serve as a resource to explore comparative aspects of canine and human endothelial tumors for therapeutic development.

\section{Materials and methods}

\section{Establishment of Cell Lines}

Viable samples were obtained from 11 family-owned pet dogs with primary (spleen, right atrium) or metastatic (liver, mesentery) lesions with gross features of visceral HSA (Table 1). Participation in the study required the dogs' owners to sign an informed consent form indicating they understood the goals and procedures for this study. Protocols and procedures were reviewed by the Institutional Review Board and Institutional Animal Care and Use Committee of AMC Cancer Research Center. Tumor explants were collected from surgical biopsy samples under sterile conditions into Dulbeccos's modified Eagle medium (Life Technologies, Bethesda, MD, USA) supplemented with $10 \%$ heat-inactivated fetal bovine serum (FBS, Hyclone, Logan, UT, USA), penicillin $(100 \mathrm{U} / \mathrm{ml})$, and streptomycin $(100 \mu \mathrm{g} / \mathrm{ml})$. Tissue was rinsed in sterile phosphate-buffered saline solution (PBS) to remove residual blood and divided into three portions that were (1) fixed in 10\% neutral buffered formalin, (2) snap frozen, and (3) minced and digested enzymatically in $0.25 \%$ trypsin and $1 \mathrm{mM}$ EDTA to establish cell cultures. Debris was removed from the samples using 120-200 $\mu \mathrm{m}$ mesh filters and cells were divided equally into six-well plates at a density of $0.3-2.5 \times 10^{6} / \mathrm{ml}$ in $3 \mathrm{ml}$ of $\mathrm{F} 12 \mathrm{~K}$ media (ATCC, Manassas, VA, USA) supplemented with 10\% FBS (Hyclone, Logan, UT, USA), endothelial growth supplements (BD Biosciences, San Jose, CA, USA), and $100000 \mathrm{IU} / \mathrm{ml}$ of high molecular weight heparin (Sigma Chemical Co., St Louis, MO, USA). Cells were cultured overnight and residual blood cells were removed by gentle aspiration. In most cases, the adherent cells expanded into heterogeneous populations that consisted of large, polygonal or 'flag'-shaped cells, rounded cells, and elongated spindle cells that resembled fibroblasts or stromal cells. The cells were then subcultured into six-well plates at a density of $0.5 \times 10^{6} / \mathrm{ml}$. In general, sublines expanded into homogeneous populations, and only those consisting of large, polygonal, or rounded cells survived beyond three passages. Cells were fed three times weekly and passaged when they reached $\sim 80 \%$ confluence. Samples also were included from one dog with cutaneous HSA where the tumor was implanted subcutaneously into an immunodeficient mouse to select cells that could form tumors in vivo. ${ }^{30}$ The cells were maintained in culture using the same conditions described above.

\section{Chemicals and Reagents}

Tissue culture materials were obtained from VWR Scientific (South Plainfield, NJ, USA) and chemicals from Sigma, unless otherwise specified. Human umbilical vein endothelial cells (HUVEC) were obtained from the ATCC and cultured in supplemented FK12 media following the ATCC recommendations. Anti-CD31 (PECAM-1) antibody (clone JC/70A) was from Dako Cytomation, (Carpinteria, CA, USA), anti-CD117 (c-Kit) antibody was from Cell Marque (Hot Springs, AR, USA), anti-CD51/ CD61 $\left(\alpha_{\mathrm{v}} \beta_{3}\right.$ integrin) antibody (mAb 1976) and antiCD146 (MUC18, S-endo) antibody (mAb 16985) were from Chemicon (Temecula, CA, USA), antiCD105 (endoglin) antibody (clone 8E11) was from

Table 1 Origin and phenotype of samples and cell lines

\begin{tabular}{|c|c|c|c|c|c|}
\hline $\operatorname{Dog} I D$ & Gender/breed & $\begin{array}{l}\text { Histologic diagnosis (site of cell line } \\
\text { origin) }\end{array}$ & $\begin{array}{l}\text { CD31 } \\
\text { expression }\end{array}$ & $\begin{array}{l}\text { CD117 } \\
\text { expression }\end{array}$ & Cell line \\
\hline Dog 1 & Male Dalmatian & Splenic HSA (spleen) & + & + & Dal-4 \\
\hline Dog 2 & Male Golden Retriever/Great Pyrenees mix & Splenic HSA (spleen) & + & + & DD-1 \\
\hline Dog 3 & Male Golden Retriever & $\begin{array}{l}\text { Splenic HSA with extensive necrosis } \\
\text { (N/A) }\end{array}$ & ND & ND & None established \\
\hline Dog 4 & Male Golden Retriever & Splenic HSA (spleen) & + & + & CHAD-G4.1 \\
\hline Dog 5 & Female Golden Retriever & $\begin{array}{l}\text { Splenic HSA with mesenteric } \\
\text { metastasis (spleen) }\end{array}$ & + & + & CHAD-G6.4 \\
\hline Dog 6 & Male Border Collie & Atrial HSA (right atrium) & + & + & CHAD-B7.4 \\
\hline Dog 7 & Male Golden Retriever & $\begin{array}{l}\text { Splenic HSA with vascular emboli } \\
\text { (spleen) }\end{array}$ & + & + & CHAD-G8.2 \\
\hline Dog 8 & Male Portuguese Water Dog & $\begin{array}{l}\text { Splenic HSA with liver metastases } \\
\text { (liver) }\end{array}$ & + & + & CHAD-P9.5 \\
\hline Dog 9 & Male German Shepherd Dog & Cutaneous HSA (subcutis) & + & ND & SB-HSA \\
\hline Dog 10 & Male Standard Poodle & Splenic hematoma (N/A) & - & - & None established \\
\hline Dog 11 & Female Labrador Retriever & Splenic hematoma (N/A) & + & - & None established \\
\hline Dog 12 & Female Golden Retriever & Splenic hematoma (N/A) & + & - & None established \\
\hline
\end{tabular}

N/A, not applicable; ND, not done. 
Southern Biotechnology Associates (Birmingham, AL, USA), and the control anti-TNP antibody (IgG ${ }_{2 \mathrm{a}}$ $\kappa)$ was from BD Biosciences. Sterile EDTA was used in culture at a concentration of $0.1 \mathrm{mM}$, nicotine tartrate salt was dissolved in HEPES-buffered saline (HBS) and used in culture at a concentration of $10 \mu \mathrm{M}$, and FK506 (Calbiochem, San Diego, CA, USA) was dissolved in $100 \%$ ethanol and used in culture at a concentration of $100 \mathrm{ng} / \mathrm{ml}$. All compounds were diluted at least 1000-fold in cell cultures. The addition of sterile water, HBS, or ethanol at $0.1 \%$ did not affect any of the parameters measured.

\section{Pathology and Immunohistochemistry}

Sections from each explant were fixed in $10 \%$ neutral buffered formalin for $24 \mathrm{~h}$. Diagnoses were made from routine H\&E stained slides using standard histopathologic criteria. HSAs were characterized by poorly demarcated and nonencapsulated proliferation of atypical ovoid to spindyloid cells. The cells proliferated as solid sheets, but often broke apart to form rudimentary and tortuous vascular channels. The cells were also markedly invasive into adjacent parenchyma. Individual cells were characterized by scant to moderate eosinophilic cytoplasm, and moderately pleomorphic, euchromatic nuclei with medium-sized nucleoli. There usually were one to two mitotic figures per high power field, and there was significant organizing hemorrhage in the adjacent, noninvolved parenchyma. Splenic hematoma specimens were characterized by poorly demarcated and nonencapsulated hemorrhage throughout the splenic parenchyma. There was early peripheral proliferation of welldifferentiated fibroblasts (fibroblastic organization), accompanied by significant hemosiderin deposition. Within the lesion, there was variable proliferation of stromal fibroblasts, fibrohistiocytic cells, and vascular endothelial cells. The adjacent noninvolved splenic parenchyma was usually normal. It is reported that splenic hematomas often form adjacent to regions of nodular lymphoid hyperplasia, which may be a predisposing factor for this lesion. ${ }^{31}$ Expression of CD31 was examined as described; ${ }^{2}$ for the detection of CD117, sections were subjected to microwave antigen retrieval in a buffer of $1 \mathrm{mM}$ EDTA, pH 8.0, and the antibody was used at a 1:50 dilution. The anti-CD117 antibody was validated in one of our laboratories (JW) using sections from CD117-positive mast cell tumors (generously provided by Dr Emily Walder, Venice, CA, USA).

\section{Flow Cytometry}

Adherent cells were washed with PBS to remove residual serum, incubated in $1 \mathrm{mM}$ EDTA for $5 \mathrm{~min}$, and detached by gentle scraping with a sterile rubber policeman. Staining buffer consisted of PBS with $0.5 \%$ bovine serum and $0.1 \%$ sodium azide. One million cells were incubated with anti-CD51/ CD61 antibody $(2 \mu \mathrm{g} / \mathrm{ml})$, anti-CD105 antibody (1:5000 dilution), or anti-CD146 antibody $(2 \mu \mathrm{g} / \mathrm{ml})$ for $30 \mathrm{~min}$ at $4^{\circ} \mathrm{C}$. An anti-TNP antibody was used as a control for nonspecific binding. Cells were then washed four times in staining buffer and incubated with a goat-anti-mouse IgG/IgM antibody conjugated to fluorescein isothiocyanate (FITC, Pharmingen, San Diego, CA, USA) for $20 \mathrm{~min}$. Cells were again washed four times in staining buffer and then fixed in $2.5 \%$ neutral buffered formalin. Samples were kept at $4{ }^{\circ} \mathrm{C}$ protected from light until analysis using a Beckman Coulter Epics XL flow cytometer (Beckman Coulter, Hialeah, FL, USA) running the Expo 32 software package. For ploidy analysis, cells were fixed in $80 \%$ ethanol and stained using propidium iodide as described. ${ }^{32}$ Analysis was carried out using the ModFit LT Software Package (Verity Software, Topsham, MA, USA).

\section{Immunofluorescence}

Expression of CD51/CD61, CD105, and CD146 was examined in live cells grown in 24-well plates (BD Discovery Systems). Adherent cells were washed three times with staining buffer and incubated with $2 \mu \mathrm{g}$ of anti-CD51/CD61 antibody, a 1:100 dilution of anti-CD105 antibody, or $2 \mu \mathrm{g}$ of anti-CD146 antibody in $200 \mu \mathrm{l}$ of staining buffer at $4^{\circ} \mathrm{C}$ for $30 \mathrm{~min}$. Cells were washed again three times with staining buffer and incubated with goat anti-mouse IgG/IgM antibody conjugated to FITC (1:2500 dilution) in $200 \mu \mathrm{l}$ of staining buffer for $30 \mathrm{~min}$. Cells were washed three times with staining buffer. After the last wash, $500 \mu \mathrm{l}$ of staining buffer was added to the wells, and cells were examined using an Olympus IX71 inverted microscope with an Olympus Microfire S79809 cooled digital camera (Scientific Instrument Company, Aurora, CO, USA). Transmitted light images under phase contrast were captured using a gain of 1.0 and exposures ranging from 12 to $60 \mathrm{~ms}$. Fluorescent images were captured using a gain setting of 4.0 and exposures ranging from 2.6 to $4 \mathrm{~s}$. Brightness and contrast for each image were optimized using Photoshop 7.0 (Adobe, San Jose, CA, USA).

\section{Anchorage-Independent Growth and Motility in Basement Membrane Matrix Media}

Semi-solid medium was prepared by mixing supplemented F12 K media with $0.6 \%$ Agar Noble (1:2, $\mathrm{v}: \mathrm{v})$ to make a bottom agar $(1 \mathrm{ml} /$ well in 24 -well plates). After $30 \mathrm{~min}$ at room temperature, $7.5 \times 10^{4}$ HSA cells were gently overlaid on the bottom agar, along with $1 \mathrm{ml}$ of top agar, consisting of $50 \%$ F12 K and 50\% 0.6 Agar Noble. Freshly thawed Matrigel Brand Basement Membrane Matrix (Collaborative 
Biomedical Products, Bedford, MA, USA) was mixed with supplemented F12 K media $(1: 1, \mathrm{v}: \mathrm{v})$ while maintaining the temperature below $8^{\circ} \mathrm{C}$. The medium was gently layered into 24-well plates (1 $\mathrm{ml} /$ well) and allowed to solidify at $37^{\circ} \mathrm{C}$ for $>2 \mathrm{~h}$. HSA cells $\left(7.5 \times 10^{4}\right.$ in $1 \mathrm{ml}$ of supplemented F12 K media) were gently overlaid on the solid Matrigel and allowed to remain undisturbed in culture at $37^{\circ} \mathrm{C}$ for at least $24 \mathrm{~h}$ before the plates were removed for microscopic examination. Cell growth, colony formation, and invasion were determined by daily examination under an Olympus IX71 inverted microscope. Transmitted light images under phase contrast were captured using a gain of 1.0 and exposures ranging from $12-60 \mathrm{~ms}$.

\section{Proliferation}

Cell proliferation was measured using the CyQuant Cell Proliferation Assay Kit (Invitrogen/ Molecular Probes, Eugene, OR, USA). Standard curves were developed using Dal-4 cells grown for $24 \mathrm{~h}$. The dynamic range of this assay covered four orders of magnitude (linear from 200 cells/well to 50000 cells/well). Replicate samples of 3000 cells were cultured in $200 \mu \mathrm{l}$ (15000 cells $/ \mathrm{ml}$ ) and frozen at $24 \mathrm{~h}$ intervals. CyQuant GR fluorescence was measured following the manufacturer's instructions.

\section{Vascular Endothelial Growth Factor Expression}

Expression of vascular endothelial growth factor-A (VEGF) mRNA was examined using reverse transcriptase-polymerase chain reaction (RT-PCR) as described. ${ }^{30}$ Cells were grown in EBM-2 media (Clontech, Palo Alto, CA, USA) containing 10\% FBS, but without endothelial growth supplements. After $6 \mathrm{~h}$ of culture, RNA was isolated using RNA Wiz (Ambion, Austin, TX, USA). Quantitative assessment of steady state levels of VEGF message was performed by Northern blotting, where $10 \mu \mathrm{g}$ of RNA was separated electrophoretically on $1 \%$ agarose $/ 5 \%$ formaldehyde denaturing gels, and the canine-specific VEGF amplification product generated for the RT-PCR reaction was used as a probe. Cell-free culture supernatants were harvested by centrifugation followed by removal of cellular debris using $0.2 \mu \mathrm{m}$ filters. VEGF was measured in the cellfree supernatants using the human VEGF Quantikine kit (R\&D Systems, Minneapolis, MN, USA) as described. ${ }^{33}$

\section{Results}

\section{Isolation of Morphologically Homogeneous Cell Lines from HSA Explants}

Surgical biopsies were collected from 10 dogs with splenic masses, one dog with a right atrial mass, and one dog with a subcutaneous mass, which were grossly consistent with HSA. Diagnosis was con-
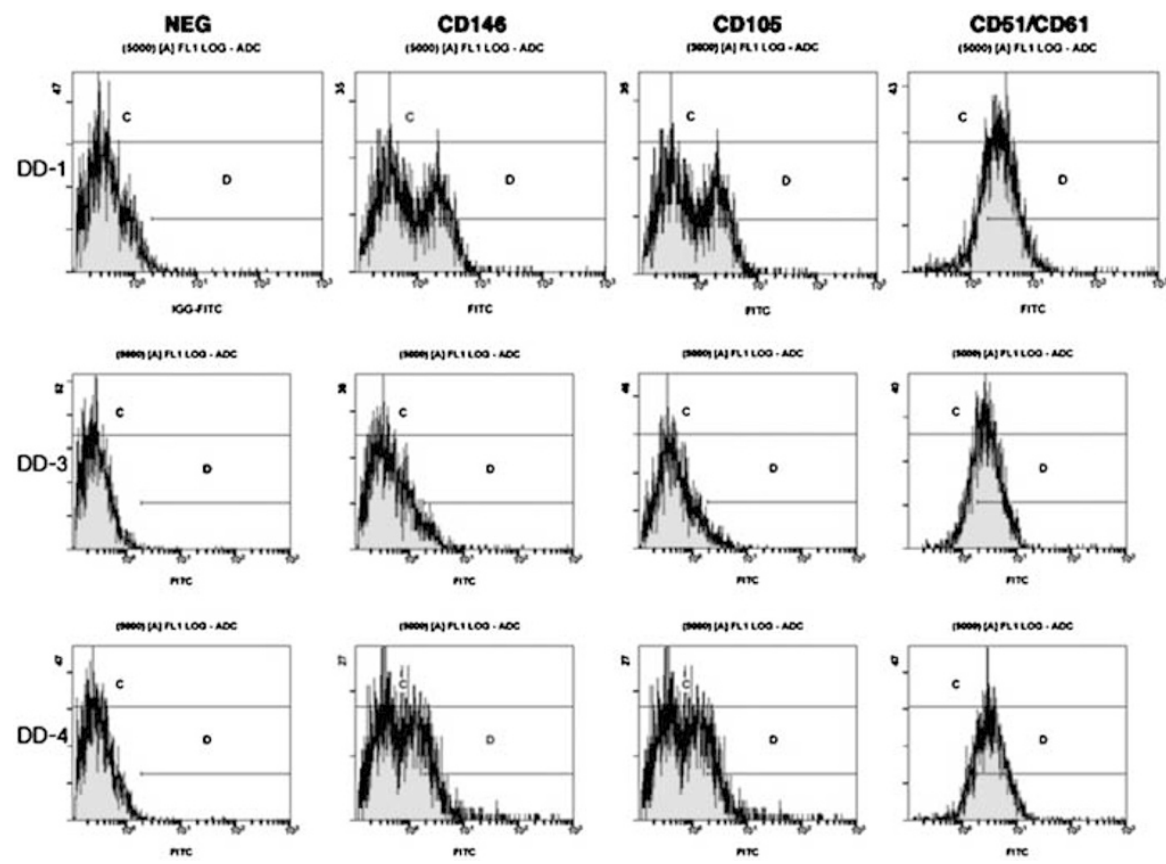

Figure 1 Expression of endothelial antigens by canine HSA sublines. The explant from Dog 2 was minced and filtered through a $200 \mu \mathrm{m}$ mesh to remove debris and obtain a single-cell suspension. This single-cell suspension was divided into six wells in a six-well plate and grown to near confluence (80-90\%) in FK12 media with endothelial growth supplement. Cells from each well were then subcultured into individual wells on new six-well plates and grown to near confluence. Cells from selected populations among these (DD-1, DD-3, DD-4) were then stained using antibodies directed to CD146, CD105, and CD51/CD61 and examined flow cytometrically to identify lines representing endothelial cells. 
firmed using standard histologic criteria and expression of CD31 and CD117 (Table 1). Two dogs (Dog 5 and Dog 8) had gross metastases to the mesentery and the liver, respectively, and one dog (Dog 7) had evidence of tumor emboli within splenic blood vessels. One sample (Dog 3) had extensive necrosis and was excluded from further analyses. CD31 expression was detectable in endothelial cells from each HSA sample and two of three benign hematomas (poorly demarcated areas of hemorrhage with proliferation of nonmalignant stromal fibroblasts, fibrohistiocytic cells, and vascular endothelial cells). In contrast, CD117 expression in endothelial cells was detectable exclusively in HSA samples and not in benign hematomas. Expression of CD117 was also detectable in endothelial cells from three additional archival HSA samples that were not included in this study because fresh tissue was not available. Viable cell lines capable of growing $>20$ passages were established from eight of nine HSA explants. On the other hand, cells derived from benign hematomas grew slowly in culture, if at all, and did not survive beyond three passages. Initially, cells isolated from the explants were moderately pleomorphic, likely because the cultures included both endothelial and stromal cells. To obtain homogeneous samples, cells were subcultured once and each derivative subline was analyzed for expression of endothelial cell antigens CD146, CD105, and CD51/CD61 (Figure 1). Sublines that showed consistent expression of at least two of these antigens were selected for further study. The cells in each subderivative line were morphologically homogeneous; however, there were notable differences among the different lines. Representative phase contrast photomicrographs from each line are shown in Figure 2. Dal-4 and CHADB7.4 cells showed spindled to polygonal morphology; DD-1, CHAD-G4.1, and CHAD-G6.4 cells showed round to square to polygonal morphology; CHAD-P9.5 cells showed spindled morphology; and SB-HSA cells were small with prominent, thin cytoplasmic dendrites. Every cell line had euchromatic nuclei with prominent nucleoli. In addition, each cell line except SB-HSA showed domed granular perinuclear zones with extensive flattening in the distal cytoplasmic regions. The cells also showed clear cytoplasmic zones that were highly refractile. Similar vacuolar structures were present extracellularly, suggesting they might represent secretory vesicles. Apoptotic cells (detached cells or those showing condensed nuclear chromatin) were seen infrequently $(<1 \%)$ in logarithmically growing cultures, but were more common $(>20 \%)$ in cells that were allowed to reach confluence. The cells also showed fastidious growth properties. Cultures showed reduced growth or complete growth arrest when cultured without endothelial growth supplements despite expression of endogenous VEGF (see below). Although some of the lines could survive up to two passages in the presence of
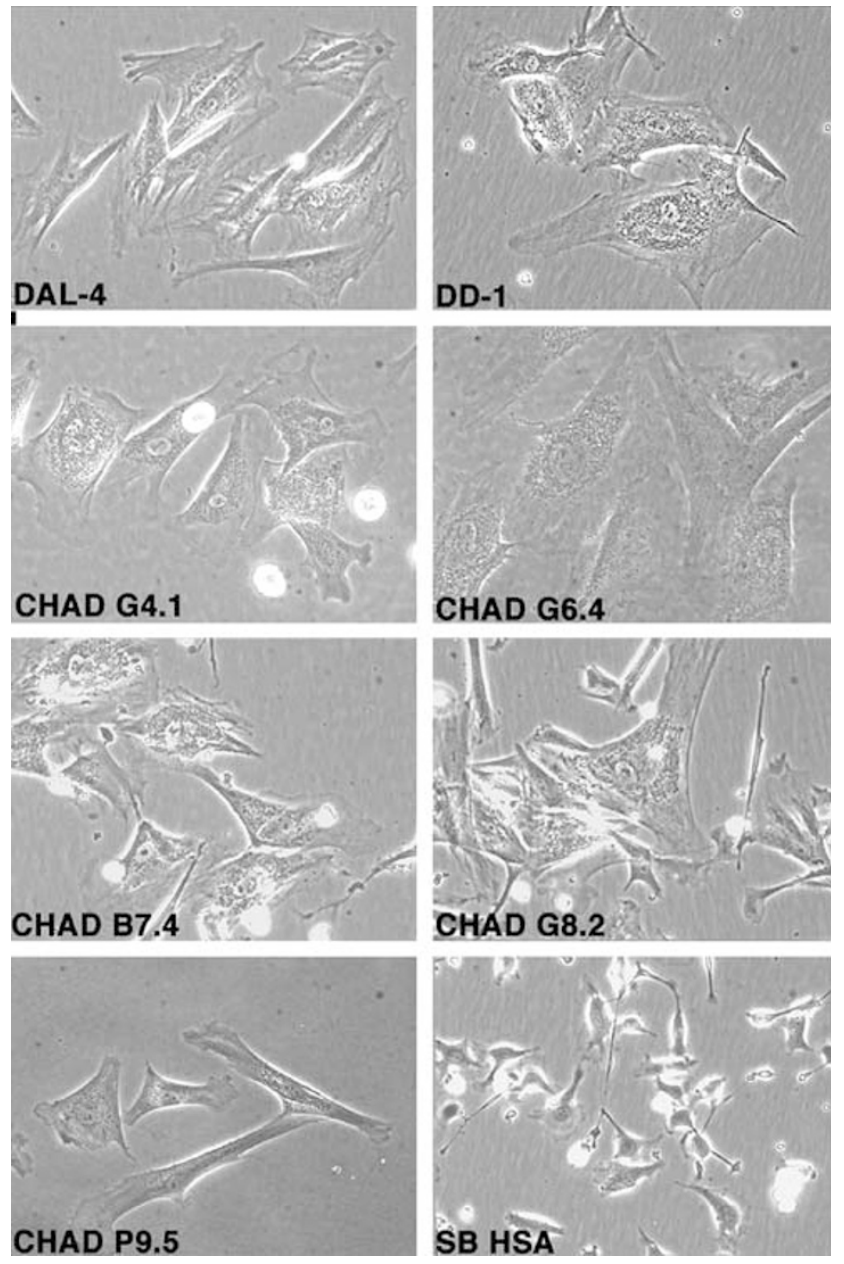

Figure 2 Morphologic appearance of canine HSA cell lines. Cell lines were maintained in culture for at least five passages and photographed under phase contrast $(\times 320$ magnification) under conditions of logarithmic growth (day 2 after passage). Images were acquired using an Olympus Microfire digital camera and assembled using Photoshop 7.0.

serum without endothelial growth supplements, they became pleomorphic and eventually died. Although the cells grew in various endothelial media formulations, they thrived in $\mathrm{F} 12 \mathrm{~K}$ media supplemented with endothelial growth factors.

Finally, to verify the stability of the cell lines, expression of CD51/61, CD105, and CD146 was reexamined in cells maintained in culture for five to eight additional passages. Figure 3 shows that expression of each antigen was retained by each cell line, although not every cell in each line expressed every antigen. The morphological features of the cells also remained consistent for at least 20 passages. Expression of CD31 and vWF was also examined in DD-1, Dal-4, and SB-HSA cells using immunocytochemistry. Each of the three cell lines expressed CD31, although the intensity of expression was variable. Expression of vWF was detectable in SB-HSA cells, at low levels in $<10 \%$ of DD-1 cells, and not in Dal-4 cells. These data are 


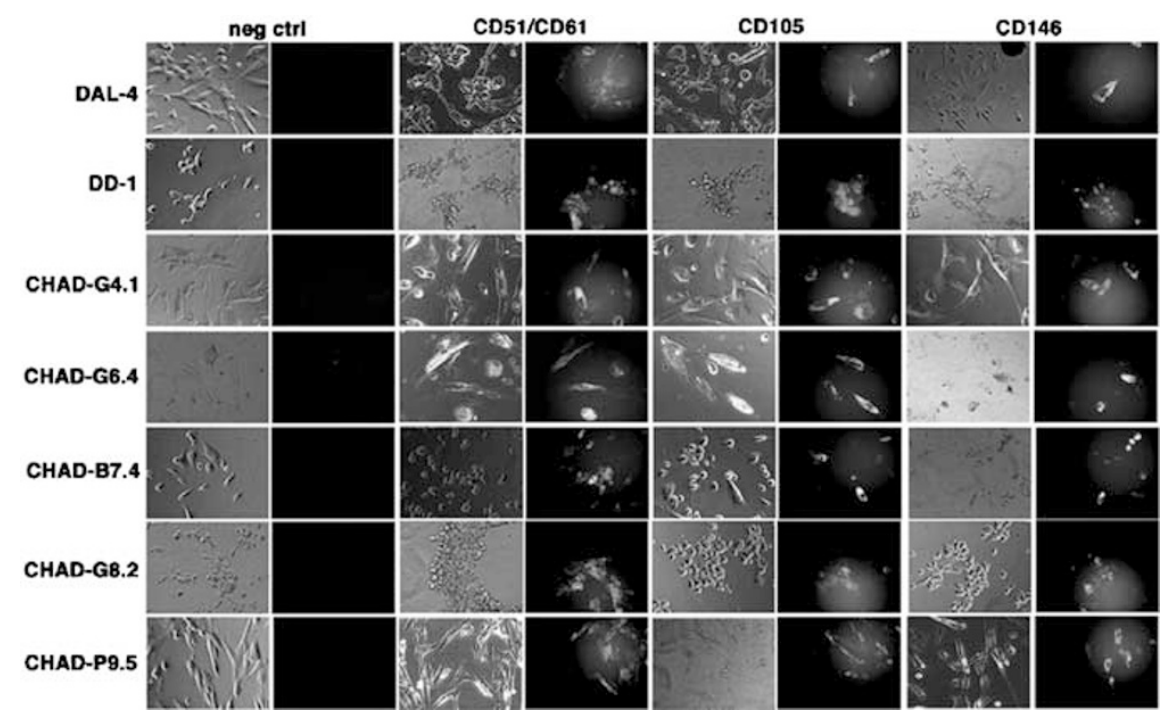

Figure 3 Expression of CD51/CD61, CD105, and CD146 in canine HSA cell lines after 5-8 passages. Cells were maintained in culture for at least five passages in the presence of endothelial growth supplements, after which they were grown in 24-well plates and stained for the endothelial antigens in the wells. Paired photomicrographs of the same field show the cells under phase contrast illumination (left) and the expression of each antigen under fluorescent illumination (right) at $\times 200$ magnification. Images were acquired using an Olympus Microfire digital camera and assembled using Photoshop 7.0.

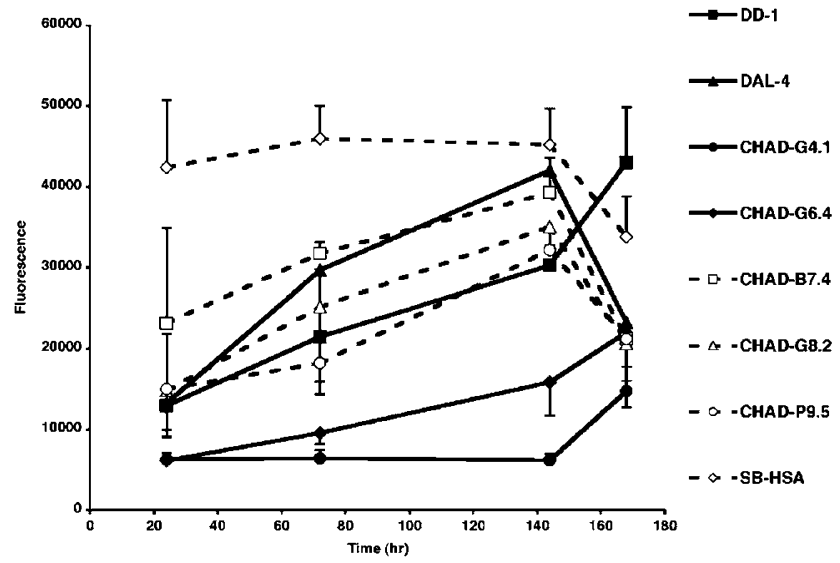

Figure 4 Proliferation of HSA cell lines. Replicate wells for each cell line containing 3000 cells in $200 \mu \mathrm{l}$ were cultured in 96-well plates, and plates were frozen at $24 \mathrm{~h}$ intervals. Proliferation was measured using the CyQuant assay. Data represent the CyQuant GR emission (measured at $495 \mathrm{~nm}$ ) as a function of time (in h). The relative rate of proliferation for each cell line corresponded closely to the time required for cells to achieve confluence (3-7 days when seeded at $5 \times 10^{5}$ cells in $5 \mathrm{ml}$ in $25 \mathrm{~cm}^{2}$ tissue culture flasks).

consistent with previously published results that suggest vWF expression may occur in later stages of differentiation and may be restricted to specific subsets of endothelial cells, ${ }^{34-36}$ and with our observation that vWF expression in canine HSA appears to localize preferentially to formed vessels rather than to solid areas of malignant cells (JW, unpublished).

\section{Growth Properties and Malignant Potential of HSA Cell Lines}

The different cell lines showed variable growth properties as determined by proliferation, anchorage-independent growth, and motility on basement membrane matrix. CHAD-G4.1 cells showed the least rapid proliferation, with a slow steady rate of DNA synthesis that increased as the density of the cells in culture approached $60 \%$ (Figure 4). CHADG6.4, CHAD-P9.5, DD-1, CHAD-G8.2, DAL-4, and CHAD-B7.4 showed progressively greater levels of DNA synthesis, with doubling times ranging from 2 to 4 days. SB-HSA cells grew rapidly with a doubling time of $\sim 20-24 \mathrm{~h}$ and maintained a consistently high steady state of DNA synthesis (Figure 4). DNA synthesis in all the HSA lines appeared to occur in defined, synchronous cycles, as it occasionally lagged from one day to the next (not shown). The reduced levels of DNA synthesis observed for each cell line except CHAD-G4.1 and CHAD G6.4 reflect exhaustion of growth factors from the media.

Analysis of DNA content showed that CHADG4.1, CHAD-P9.5, and SB-HSA cell lines each contained aneuploid populations, including tetraploid and hypotetraploid cells that proliferated along with the diploid populations (Figure 5). The remaining cell lines had diploid DNA content. Cells recovered from a hematoma explant (Dog 10) were $100 \%$ diploid and largely in G0/G1 (>90\%), whereas the cell cycle distribution of HSA cell lines after 3 days in culture reflected active proliferation (70-80\% of cells in G1 and $20-30 \%$ of cells in S/G2/ M). Despite the fact that five lines had diploid 

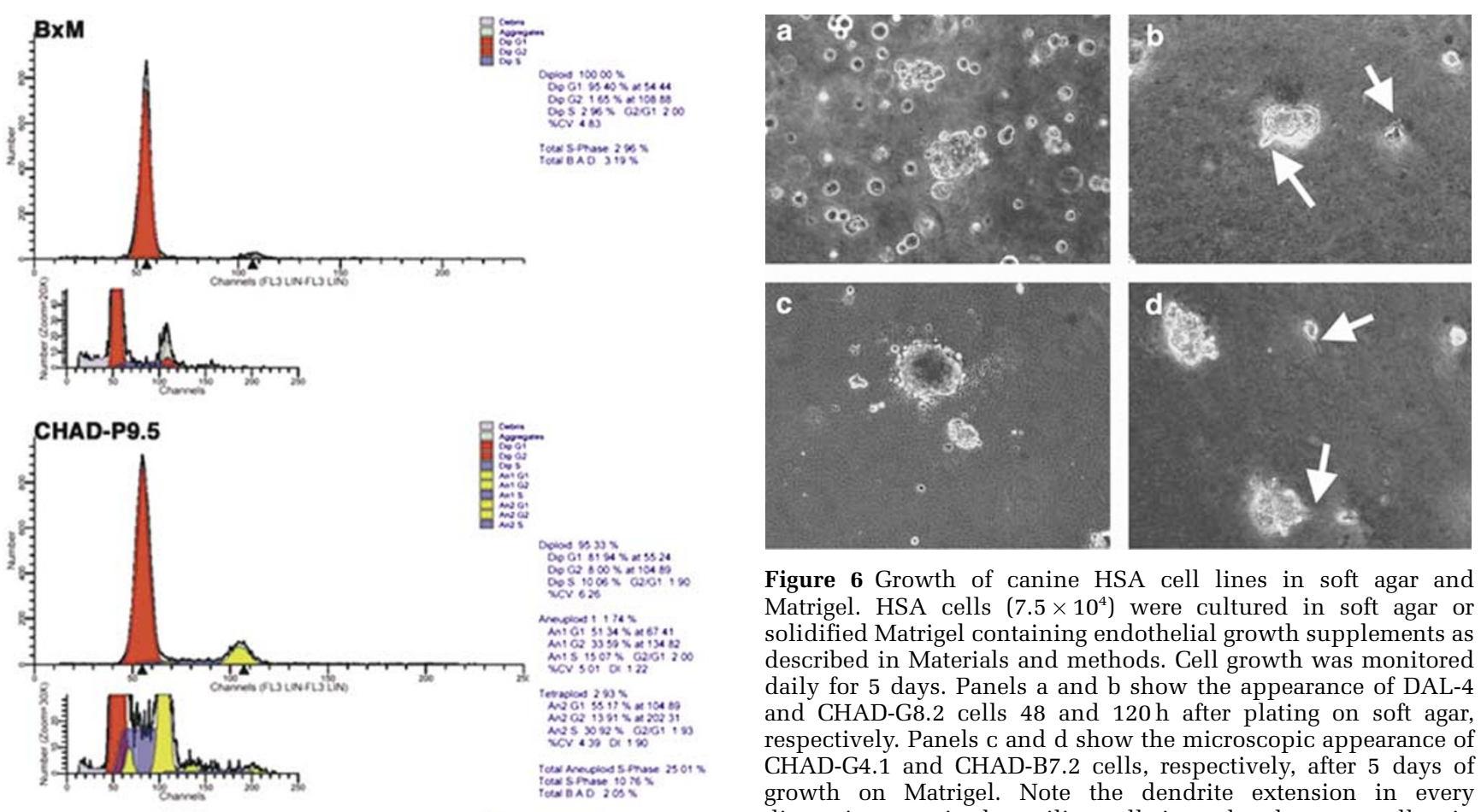

Figure 6 Growth of canine HSA cell lines in soft agar and Matrigel. HSA cells $\left(7.5 \times 10^{4}\right)$ were cultured in soft agar or solidified Matrigel containing endothelial growth supplements as described in Materials and methods. Cell growth was monitored daily for 5 days. Panels a and b show the appearance of DAL-4 and CHAD-G8.2 cells 48 and $120 \mathrm{~h}$ after plating on soft agar, respectively. Panels $\mathrm{c}$ and $\mathrm{d}$ show the microscopic appearance of CHAD-G4.1 and CHAD-B7.2 cells, respectively, after 5 days of growth on Matrigel. Note the dendrite extension in every dimension seen in the trailing cells in each colony, as well as in individualized cells (arrows).

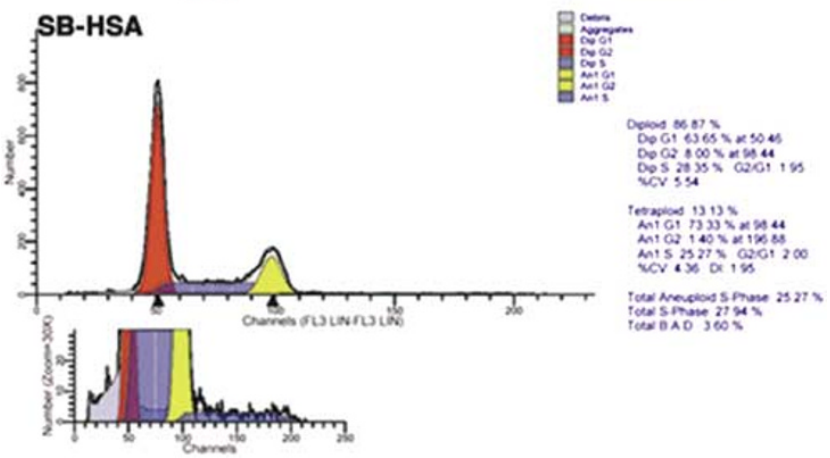

Figure 5 DNA content of representative HSA cell lines. Cells in the logarithmic growth phase were fixed in $80 \% \mathrm{EtOH}$, treated with RNase A $(25 \mu \mathrm{g} / \mathrm{ml})$, stained with propidium iodide $(25 \mu \mathrm{g} /$ $\mathrm{ml}$ ), and analyzed flow cytometrically. Ploidy and cell cycle distribution were determined using best-fit analysis on the ModFit software. DNA histograms are shown for hematoma cells isolated from Dog 12 (BxM), CHAD-P9.5, and SB-HSA; a magnified view is shown below the main histogram for each line to show the $\mathrm{S}$ phase and aneuploid populations. In all $100 \%$ of the cells in the DD-1, DAL-4, CHAD-G6.4, CHAD-B7.4, and CHAD-G8.2 lines had diploid DNA content, but the G1 peaks accounted for $70-80 \%$ of the cells. Approximately $7.5 \%$ of cells in the CHAD-G4.1 line were tetraploid, excluding the diploid cells in $\mathrm{G} 2 / \mathrm{M}$.

DNA content, analysis of metaphase chromosomes from early passages $(<3)$ showed that the HSA cells generally had complex and unstable karyotypes that included complete chromosome fusions, segmental deletions, and translocations (data not shown).

Anchorage-independent growth, motility, and invasion are common features of malignant cells. To examine anchorage-independent growth of HSA cells, $6 \times 10^{4}$ cells were cultured in $2 \mathrm{ml}$ of soft agar

media containing endothelial growth supplements in 24-well plates. Motility and invasion on basement membrane matrix were analyzed under similar conditions using a commercial Matrigel ${ }^{\mathrm{TM}}$ formulation. Cells plated in soft agar remained individualized for the first $24 \mathrm{~h}$. Within $48 \mathrm{~h}$, small colonies were visible (Figure 6a) and these continued to expand for the 3 subsequent days (Figure 6b). Each cell line was capable of anchorage-independent growth, but few viable colonies were visible for CHAD-G7.4, CHAD-P9.5, and SB-HSA by day 5 of culture in soft agar. Cells plated in Matrigel showed similar behavior, except that the trailing cells in each colony as well as individualized cells showed dendrite extension in every dimension, consistent with a 'crawling' or motile phenotype (Figure 6c, d, arrows). Various factors control the angiogenic switch and vessel formation by endothelial cells. The transcription factors in the nuclear factor of activated T Cells (NFAT) family control various aspects of angiogenesis and metastasis, including VEGF production and invasion. ${ }^{37,38}$ To examine the role of NFAT factors in HSA cell motility, cell lines were cultured in 24-well plates in the absence of endothelial growth supplements and under conditions of low calcium ( $0.1 \mathrm{mM}$ EDTA) with the calcineurin/NFAT antagonist FK506 $(100 \mathrm{ng} / \mathrm{ml})$. Untreated cells remained individualized in a monolayer (see Figures 2 and 3). In contrast, eight of 10 cells lines treated with EDTA and FK506 showed active migration after $4-6 \mathrm{~h}$ that led to the formation of elongated tubular structures with end buds that resembled blood vessels (Figure 7). Intriguingly, Dal- 

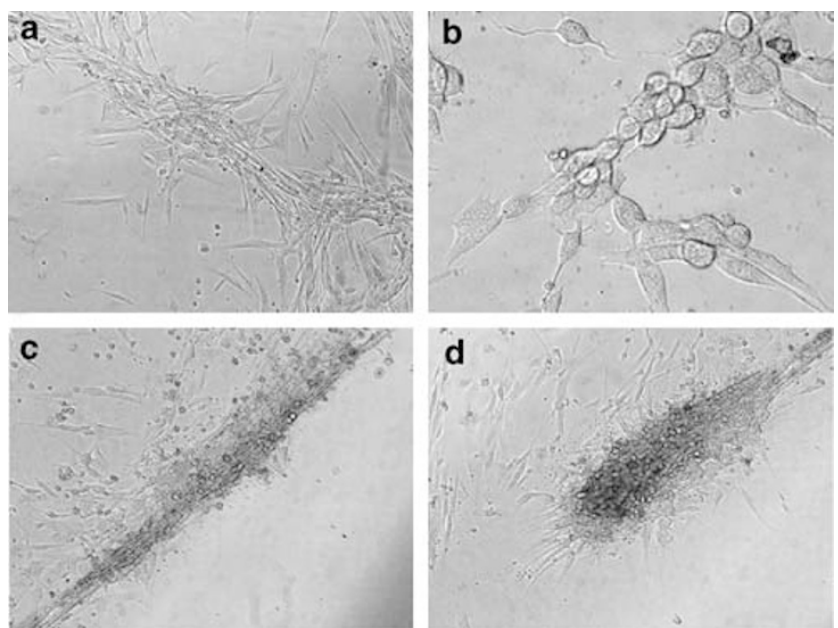

Figure 7 Aggregation of canine HSA cell lines into tubular structures. HSA cell lines were cultured under conditions of low calcium (0.1 mM EDTA) with FK506 (100 ng/ml) without endothelial growth supplements. Cells were examined microscopically after $4-6 \mathrm{~h}$ under phase contrast illumination. Panel a shows an example of DD-1 cells ( $\times 100$ magnification) and panel $b$ shows an example of DAL-4 cells $(\times 320$ magnification $)$ to illustrate the active migration and aggregation of cells to form elongated structures. Panels $\mathrm{c}$ and $\mathrm{d}$ are photomicrographs of CHAD-G8.2 cells ( $\times 100$ magnification) illustrating a vessel-like structure and an end bud, respectively.

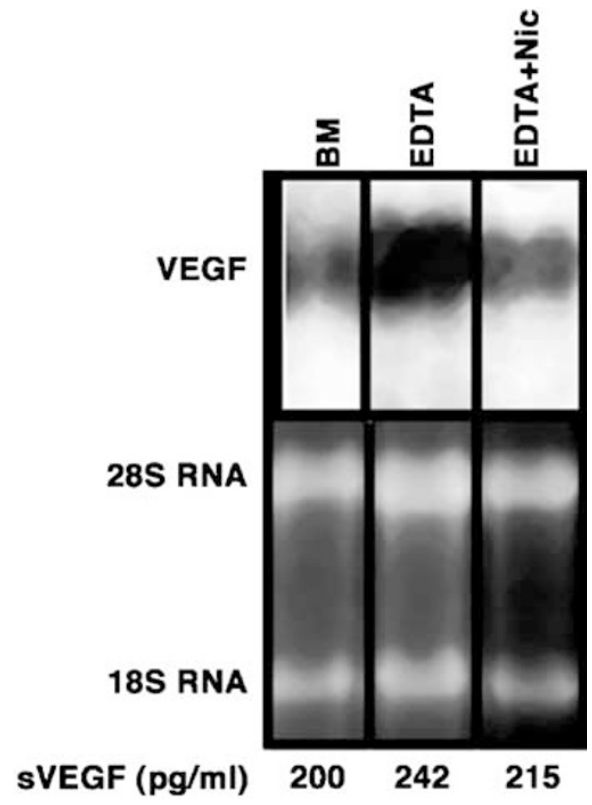

Figure 8 Increased VEGF expression in endothelial cells that form tubular structures. DD-1 cells were cultured in basal media (BM, without endothelial growth supplements), basal media under conditions of low calcium (0.1 mM EDTA), or basal media with EDTA and nicotine $(10 \mu \mathrm{M})$, an activator of NFAT transcription factors, for $6 \mathrm{~h}$. Cell-free supernatants were collected by centrifugation and cellular debris was removed by filtration. The levels of VEGF in the culture supernatants (sVEGF) were determined using a commercial ELISA following the manufacturer's instructions. VEGF gene expression was examined by Northern blotting. Ribosomal RNA bands (28S and 18S) stained with ethidium bromide are shown as loading controls.
4 and DD-1 cells showed this aggregation phenomenon when cultured in EDTA alone, and this was associated with increased VEGF gene expression and VEGF in culture supernatants (Figure 8). Aggregation in these cells was inhibited if they were cultured with nicotine, which is an activator of NFAT (Frazer-Abel et al, manuscript submitted). This was associated with the concomitant reduction of VEGF message and protein back to basal levels, suggesting that modulation of endogenous VEGF (and probably other proangiogenic factors) could offer a strategy to induce terminal differentiation of these tumors.

\section{Discussion}

We describe the characteristics of eight independent endothelial cell lines derived from explants of canine HSA. Each cell line was derived from endothelial tumors (based on expression of CD31). In addition, our results suggest that expression of CD117 (c-Kit) may offer a sensitive way to distinguish benign canine hematoma (negative) from malignant canine HSA (positive), at least in the spleen. CD117 is the receptor for stem cell factor and is expressed by hematopoietic stem cells and by most primitive hematopoietic-derived cells. ${ }^{39} \mathrm{~A}$ previous study showed that CD117 expression was detectable in human fetal capillary vessels, but not adult endothelial cells. ${ }^{40}$ The same study showed high levels of CD117 expression in $56 \%(28 / 50)$ of human angiosarcomas, but the protein was undetectable in 10 epithelioid hemangioendotheliomas and 31 hemangiomas. This is consistent with our findings, and indicates that malignant canine HSA and human angiosarcoma originate from primitive, poorly differentiated endothelial cells that can be identified by CD117 expression, whereas human hemangiomas and the proliferative vascular cells seen in canine hematomas originate from mature, differentiated endothelial cells. This observation may offer not only a significant advancement to improve the diagnosis of canine HSA and human angiosarcoma, but also an appealing target for therapeutic development.

Our results show that HSA cell lines retain expression of endothelial-associated antigens including CD31, CD146, CD105, and CD51/CD61, and as such resemble HUVEC and bovine aortic endothelial cells (BAEC) that are commonly used for studies of angiogenesis. ${ }^{41-45}$ However, expression of these antigens was limited to subsets of cells within each HSA line, and some of the lines did not express vWF. This could reflect the incomplete differentiation of the cells or absence of environmental signals that upregulate vWF expression. Alternatively, it could also be due to differential regulation of expression during the cell cycle, and it could also reflect inherent instability within the cell lines. Cytogenetic analysis of these cells showed complex, 
unstable karyotypes, and at least three cell lines showed evidence of aneuploidy. This is not unexpected, since genetic instability is a hallmark of most tumors, ${ }^{46}$ and the populations in the tumor explants are likely to reflect extensive clonal evolution. Moreover, while this may raise a cautionary note regarding the use of these lines for preclinical development and for studies to elucidate the pathogenesis of canine HSA, HUVEC are hypodiploid (ATCC, technical details for CRL-1730, HUVEC-C), and in our experiments, expression of endothelial antigens in HUVEC was similarly variable and restricted to subsets within the population (not shown). The suitability of canine HSA cells as models to study tumor neoangiogenesis is further underscored by the similarities between the endothelial structures in these tumors and pericytepoor, thin-walled 'mother vessels' that are formed during the early response of endothelial cells to elevated concentrations of VEGF, as well as during the process of tumor neoangiogenesis. ${ }^{47}$ These mother vessels are leaky and can evolve into tortuous, poorly organized vessels that are predisposed to thrombosis, similar to what is seen in primary canine HSA.

The canine HSA cell lines we describe retain some features of normal growth, such as the requirement for endothelial growth factors. They also show contact inhibition and can be induced to form elongated tubular structures that resemble blood vessels, suggesting they are capable of differentiation. However, they also show characteristic features of malignant behavior, including anchorage-independent growth and three-dimensional motility on Matrigel. The capability to form vessels upon inactivation of calcium-dependent signaling pathways, including inhibition of NFAT, is especially intriguing. The activity of NFAT transcription factors is exquisitely regulated by alterations in intracellular calcium levels. These factors are expressed ubiquitously; NFATc1 and NFATc4 are highly expressed in the heart and endothelial cells. ${ }^{48,49}$ NFATc2 is the major form present in activated lymphocytes, and NFATc3 is the major form expressed in thymocytes, although both these proteins are also expressed outside of the immune system. The importance of NFAT proteins in endothelial cell growth and function was demonstrated by results from de la Pompa ${ }^{50}$ and Graef ${ }^{37}$ showing that NFATc1 deficiency resulted in embryonic lethality due to defects in cardiac morphogenesis, and mice deficient for calcineurin-B (which is required for NFAT activation) or doubly deficient for NFATc4 and NFATc3 were not viable due to vascular developmental abnormalities that included defective blood vessel assembly, despite (or possibly because of) increased production of VEGF and increased expression of the Flt-1 VEGF receptor. We have shown previously that nicotine is an activator of NFAT proteins (Frazer-Abel et al, manuscript submitted). Curiously, nicotine has been shown to increase VEGF production and endothelial cell proliferation in various models of angiogenesis. ${ }^{51-54}$ The discrepancy between those results and the reduction in VEGF expression we show here may reflect differences in VEGF production and utilization between mature, differentiated endothelial cells and primitive HSA cells. Thus, elevated levels of VEGF may drive proliferation of mature endothelial cells, but they may induce differentiation of primitive endothelial cells. However, an alternative interpretation of the observation that nicotine prevents the formation of tube-like structures is that the apparent mitogenic effect of nicotine on endothelial cells may be, at least in part, due to a failure of differentiation, and that this effect is mediated by NFAT activation. This interpretation is also consistent with the recent observation that activation of NFATc2 (NFAT1) and NFAT5 was an important mediator of the invasive phenotype in human breast cancer cells, ${ }^{38}$ and invasion required signaling through $\alpha_{6} \beta_{4}$ integrin. While the role of $\alpha_{v} \beta_{3}$ integrins (CD51/CD61) in blood vessel formation is well established, ${ }^{55,56}$ the possibility that signals delivered through CD51/CD61 and NFATdependent events may contribute to the invasive phenotype of neoangiogenic endothelial cells remains to be determined. Similarly, the possibility that exposure to environmental tobacco smoke may contribute to the pathogenesis of canine HSA should be carefully explored.

In summary, we describe eight cell lines derived from canine malignant endothelial tumors that offer a much needed resource to study the pathogenesis of canine HSA, provide desirable models to assess therapeutic strategies in vitro and in vivo, and offer a novel system for the study of endothelial biology and neoangiogenesis in cancer.

\section{Acknowledgements}

We gratefully acknowledge the assistance of the veterinarians and owners, respectively, who provided samples and who allowed participation of their dogs in this study. We wish to thank Karen Helm and Mike Ashton for assistance with flow cytometry, and Pepper Schedin for assistance with Matrigel assays and helpful suggestions. Supported in part by Grant 2025 from the AKC Canine Health Foundation to SCH, Grant 0791 from the Smokeless Tobacco Research Council, a grant from the Philip Morris External Research Program, and Grant 1 R55 CA86432 from the NCI to JFM, and by a grant from the Monfort Family Foundation to the University of Colorado Cancer Center. Canine molecular cytogenetics research at NCSU is supported by funds from the AKC Canine Health Foundation to MB. SRB and HM were supported in part by an educational grant (R25 CA49981) from the NCI. The University of Colorado Cancer Center Flow Cytometry Core is supported by Grant 5 P30 CA46934 from the NCI. 


\section{References}

1 von Beust BR, Suter MM, Summers BA. Factor VIIIrelated antigen in canine endothelial neoplasms: an immunohistochemical study. Vet Pathol 1988;25: 251-255.

2 Ferrer L, Fondevila D, Rabanal RM, et al. Immunohistochemical detection of CD31 antigen in normal and neoplastic canine endothelial cells. J Comp Pathol 1995;112:319-326.

3 Oksanen A. Haemangiosarcoma in dogs. J Comp Pathol 1978;88:585-595.

4 Brown NO, Patnaik AK, MacEwen EG. Canine hemangiosarcoma: retrospective analysis of 104 cases. J Am Vet Med Assoc 1985;186:56-58.

5 Clifford CA, Mackin AJ, Henry CJ. Treatment of canine hemangiosarcoma: 2000 and beyond. J Vet Intern Med 2000;14:479-485.

6 Sorenmo K, Duda L, Barber L, et al. Canine hemangiosarcoma treated with standard chemotherapy and minocycline. J Vet Intern Med 2000;14:395-398.

7 Sorenmo KU, Jeglum KA, Helfand SC. Chemotherapy of canine hemangiosarcoma with doxorubicin and cyclophosphamide. J Vet Intern Med 1993;7:370-376.

8 Hammer AS, Couto CG, Filppi J, et al. Efficacy and toxicity of VAC chemotherapy (vincristine, doxorubicin, and cyclophosphamide) in dogs with hemangiosarcoma. J Vet Intern Med 1991;5:160-166.

9 Fedok FG, Levin RJ, Maloney ME, et al. Angiosarcoma: current review. Am J Otolaryngol 1999;20:223-231.

10 Hai SA, Genato R, Gressel I, et al. Primary splenic angiosarcoma: case report and literature review. J Natl Med Assoc 2000;92:143-146.

11 Budd GT. Management of angiosarcoma. Curr Oncol Rep 2002;4:515-519.

12 Lewis R. Vinyl chloride and polyvinyl chloride. Occup Med 1999;14:719-742.

13 Lewis R, Rempala G. A case-cohort study of angiosarcoma of the liver and brain cancer at a polymer production plant. J Occup Environ Med 2003;45: 538-545.

14 Joshi MG, Crosson AW, Tahan SR. Paget's disease of the nipple and angiosarcoma of the breast following excision and radiation therapy for carcinoma of the breast. Mod Pathol 1995;8:1-4.

15 Sener SF, Milos S, Feldman JL, et al. The spectrum of vascular lesions in the mammary skin, including angiosarcoma, after breast conservation treatment for breast cancer. J Am Coll Surg 2001;193:22-28.

16 Fineberg S, Rosen PP. Cutaneous angiosarcoma and atypical vascular lesions of the skin and breast after radiation therapy for breast carcinoma. Am J Clin Pathol 1994;102:757-763.

17 Otis CN, Peschel R, McKhann C, et al. The rapid onset of cutaneous angiosarcoma after radiotherapy for breast carcinoma. Cancer 1986;57:2130-2134.

18 Martin MB, Kon ND, Kawamoto EH, et al. Postmastectomy angiosarcoma. Am Surg 1984;50:541-545.

19 Sordillo EM, Sordillo PP, Hajdu SI. Primary hemangiosarcoma of the spleen: report of four cases. Med Pediatr Oncol 1981;9:319-324.

20 Ensoli B, Sgadari C, Barillari G, et al. Biology of Kaposi's sarcoma. Eur J Cancer 2001;37:1251-1269.

21 Bell CD. Endothelial cell tumors. Microsc Res Tech 2003;60:165-170.

22 Benjamin SA, Lee AC, Angleton GM, et al. Mortality in beagles irradiated during prenatal and postnatal development. II. Contribution of benign and malignant neoplasia. Radiat Res 1998;150:330-348.

23 Timaran CH, Grandas OH, Bell JL. Hepatic angiosarcoma: long-term survival after complete surgical removal. Am Surg 2000;66:1153-1157.

24 de la Hoz C, Baroja A. Proliferative behaviour of highploidy cells in two murine tumour lines. J Cell Sci 1993;104(Part 1):31-36.

25 Unger RE, Krump-Konvalinkova V, Peters K, et al. In vitro expression of the endothelial phenotype: comparative study of primary isolated cells and cell lines, including the novel cell line HPMEC-ST1.6R. Microvasc Res 2002;64:384-397.

26 Hoover ML, Vetvicka V, Hoffpauir JM, et al. Human endothelial cell line from an angiosarcoma. In Vitro Cell Dev Biol 1993;29A(3 Pt 1):199-202.

27 Masuzawa M, Fujimura T, Hamada Y, et al. Establishment of a human hemangiosarcoma cell line (ISOHAS). Int J Cancer 1999;81:305-308.

28 Krump-Konvalinkova V, Kleideiter E, Friedrich U, et al. Tumorigenic conversion of endothelial cells. Exp Mol Pathol 2003;75:154-159.

29 Zvibel I, Raz A. The establishment and characterization of a new BALB/c angiosarcoma tumor system. Int J Cancer 1985;36:261-272.

30 Akhtar N, Padilla M, Dickerson EB, et al. Interleukin12 inhibits tumor growth in a novel angiogenesis canine hemangiosarcoma xenograft model. Neoplasia 2004;6:(in press).

31 Spangler WL, Culbertson MR. Prevalence, type, and importance of splenic diseases in dogs: 1480 cases (1985-1989). J Am Vet Med Assoc 1992;200:829-834.

32 Modiano JF, Ritt MG, Wojcieszyn J, et al. Growth arrest of melanoma cells is differentially regulated by contact inhibition and serum deprivation. DNA Cell Biol 1999;18:357-367.

33 Clifford CA, Hughes D, Beal MW, et al. Vascular endothelial growth factor concentrations in body cavity effusions in dogs. J Vet Intern Med 2002; 16:164-168.

34 Balconi G, Spagnuolo R, Dejana E. Development of endothelial cell lines from embryonic stem cells: a tool for studying genetically manipulated endothelial cells in vitro. Arterioscler Thromb Vasc Biol 2000;20: 1443-1451.

35 Kuzu I, Bicknell R, Harris AL, et al. Heterogeneity of vascular endothelial cells with relevance to diagnosis of vascular tumours. J Clin Pathol 1992;45:143-148.

36 Poblet E, Gonzalez-Palacios F, Jimenez FJ. Different immunoreactivity of endothelial markers in well and poorly differentiated areas of angiosarcomas. Virchows Arch 1996;428:217-221.

37 Graef IA, Chen F, Chen L, Kuo A, Crabtree GR. Signals transduced by $\mathrm{Ca}(2+) /$ calcineurin and NFATc3/c4 pattern the developing vasculature. Cell 2001;105: 863-875.

38 Jauliac S, Lopez-Rodriguez C, Shaw LM, et al. The role of NFAT transcription factors in integrin-mediated carcinoma invasion. Nat Cell Biol 2002;4:540-544.

39 Yoshida H, Takakura N, Hirashima M, et al. Hematopoietic tissues, as a playground of receptor tyrosine kinases of the PDGF-receptor family. Dev Comp Immunol 1998;22:321-332.

40 Miettinen M, Sarlomo-Rikala M, Lasota J. KIT expression in angiosarcomas and fetal endothelial cells: lack of mutations of exon 11 and exon 17 of C-kit. Mod Pathol 2000;13:536-541. 
41 Zimrin AB, Villeponteau B, Maciag T. Models of in vitro angiogenesis: endothelial cell differentiation on fibrin but not matrigel is transcriptionally dependent. Biochem Biophys Res Commun 1995;213: 630-638.

42 Rhim JS, Tsai WP, Chen ZQ, et al. A human vascular endothelial cell model to study angiogenesis and tumorigenesis. Carcinogenesis 1998;19:673-681.

43 Nakatsu MN, Sainson RC, Aoto JN, et al. Angiogenic sprouting and capillary lumen formation modeled by human umbilical vein endothelial cells (HUVEC) in fibrin gels: the role of fibroblasts and Angiopoietin-1. Microvasc Res 2003;66:102-112.

44 Tille JC, Wood J, Mandriota SJ, et al. Vascular endothelial growth factor (VEGF) receptor-2 antagonists inhibit VEGF- and basic fibroblast growth factorinduced angiogenesis in vivo and in vitro. J Pharmacol Exp Ther 2001;299:1073-1085.

45 Lee MS, Moon EJ, Lee SW, et al. Angiogenic activity of pyruvic acid in in vivo and in vitro angiogenesis models. Cancer Res 2001;61:3290-3293.

46 Nowell PC. The clonal evolution of tumor cell populations. Science 1976;194:23-28.

47 Pettersson A, Nagy JA, Brown LF, et al. Heterogeneity of the angiogenic response induced in different normal adult tissues by vascular permeability factor/vascular endothelial growth factor. Lab Invest 2000;80:99-115.
48 Crabtree GR, Olson EN. NFAT signaling: choreographing the social lives of cells. Cell 2002;109(Suppl):S67-S79.

49 Kiani A, Rao A, Aramburu J. Manipulating immune responses with immunosuppressive agents that target NFAT. Immunity 2000;12:359-372.

50 de la Pompa JL, Timmerman LA, Takimoto $\mathrm{H}$, et al. Role of the NF-ATc transcription factor in morphogenesis of cardiac valves and septum. Nature 1998;392: 182-186.

51 Zhu BQ, Heeschen C, Sievers RE, et al. Second hand smoke stimulates tumor angiogenesis and growth. Cancer Cell 2003;4:191-196.

52 Heeschen C, Weis M, Aicher A, et al. A novel angiogenic pathway mediated by non-neuronal nicotinic acetylcholine receptors. J Clin Invest 2002;110:527-536.

53 Heeschen C, Jang JJ, Weis M, et al. Nicotine stimulates angiogenesis and promotes tumor growth and atherosclerosis. Nat Med 2001;7:833-839.

54 Villablanca AC. Nicotine stimulates DNA synthesis and proliferation in vascular endothelial cells in vitro. J Appl Physiol 1998;84:2089-2098.

55 Friedlander M, Brooks PC, Shaffer RW, et al. Definition of two angiogenic pathways by distinct alpha $\mathrm{V}$ integrins. Science 1995;270:1500-1502.

56 Soldi R, Mitola S, Strasly M, et al. Role of alpha-v/beta3 integrin in the activation of vascular endothelial growth factor receptor-2. EMBO J 1999;18:882-892. 